\title{
The influence of processing speed on the properties of laser surface deposits
}

\author{
V. Ocelík, I. Hemmati \& J. Th. M. De Hosson \\ Department of Applied Physics, University of Groningen, The Netherlands
}

\begin{abstract}
In this paper the influence of high cooling rate which is typical for laser surface engineering techniques, on the microstructure and properties of iron based laser deposits is studied experimentally. Four different Fe-based materials were deposited using laser cladding with powder injection at speeds that vary over a few orders of magnitudes. The microstructure of the coatings, type and quantity of their constituent phases were characterized using Scanning Electron Microscopy, Energy Dispersive Spectroscopy and Electron Backscatter Diffraction. The hardness was measured using Vickers indentation.

With increasing cooling rate, the characteristic microstructure size decreases and the inter-dendritic phases became more refined for all coatings. However, the hardness behaves differently depending on the main contributing strengthening mechanism. The effect of cooling rates on the characteristic microstructure size, phase constitution, martensitic transformation and the interplay between the various strengthening mechanisms in producing the overall hardness of the iron based deposits will be discussed and explained.

Keywords: laser cladding, microstructure, steel, hardness, electron microscopy.
\end{abstract}

\section{Introduction}

An important characteristic of laser deposition technologies is the high rate of cooling during solidification which is believed to improve the functional properties of the deposits such as hardness, strength and wear resistance [1-3]. Deposition at higher laser scanning speeds will increase the solidification interface growth velocity and establishes steeper temperature gradients which in turn result in higher cooling rates $[1,4]$. In addition to increasing the cooling rate and of course reducing the processing time, higher cladding speed is reported to 
improve the energy efficiency of the process $[5,6]$. The motivation to increase the scan velocity during the laser cladding process stems from these benefits. On the other hand, cladding at higher speeds increases the risks of forming defects, e.g. crack and porosity, in the clad layers [7]. Furthermore, there are other ways such as induction-assisted laser cladding to achieve higher deposition rates without increasing the processing speed [8].

This research intends to provide a complete picture about the role of strengthening mechanism in the correlation between cladding speed and hardness of iron based laser-clad coatings. The aim is to answer the question of whether faster laser cladding of steel coatings and hence accepting the higher risk of forming defects is counterbalanced by a significant improvement in the hardness of these coatings. For this purpose, four alloys namely: Metco 42C (equivalent to AISI 431) martensitic stainless steel, Metco 41C (equivalent to AISI 316L), Höganäs 3533-00 and Carpenter MicroMelt 23 (equivalent to AISI M3) were deposited at various processing speeds and studied in detail. These alloys were selected because they are strengthened by various mechanisms including martensitic transformation (42C), homogeneous and heterogeneous interface strengthening (41C), homogeneous and heterogeneous interface strengthening plus carbides formation (3533) and martensite plus carbides formation (MicroMelt 23).

\section{Experimental}

Metco 42C, Metco 41C, Höganäs 3533-00 and Carpenter MicroMelt 23 (MM23) were deposited on a low carbon steel rod at room temperature using a continuous wave IPG fiber laser (wavelength: $1.07 \mu \mathrm{m}$ ). Chemical compositions of the cladding materials are listed in Table 1.

Powder feeding system consisted of Metco Twin 10C powder feeder, argon as carrier and shielding gas and a side cladding nozzle. For each alloy, 5 tracks with $33 \%$ overlapping were deposited at scanning speeds, ranging from 1 to $117 \mathrm{~mm} / \mathrm{s}$. Laser power and powder feeding rates were adjusted to obtain coatings with a thickness of $0.8-1.1 \mathrm{~mm}$ and a dilution of less than 10 percent. The dilution from the substrate was measured using optical microscopy images by dividing the surface area of the deposited layer to the total area of the deposited layer plus remelted substrate [9]. Samples for Scanning Electron Microscopy (SEM), Energy Dispersive Spectroscopy (EDS) and Electron Backscatter Diffraction (EBSD) analyses were cut from the transversal and longitudinal cross sections and prepared by mechanical grinding with suspensions containing 9, 3, 1 and $0.4 \mu \mathrm{m}$ diamond particles followed by final polishing using colloidal $\mathrm{Al}_{2} \mathrm{O}_{3}$. A Philips XL30 Field Emission Gun SEM equipped with EDS and EBSD systems was used to perform microstructural analysis and phase characterization.

A combination of EDS (at 5 or $20 \mathrm{kV}$ ) and EBSD (at $30 \mathrm{kV}$ ) was used to identify the phases and to measure their fractions using the hardware, software and procedures described elsewhere [10]. The characteristic sizes (i.e. secondary dendritic arm spacing or cell widths) were measured from SEM images. Cooling 
rates of the clad layers were estimated by an analytical model [11] using the parameters from [12]. Hardness of the coatings was measured on transversal cross sections using Vickers indenter at a load of $4.9 \mathrm{~N}$.

Table 1: Nominal chemical compositions of clad materials.

\begin{tabular}{cccccccccc}
\hline Mater & Fe & Cr & Ni & Mo & W & V & Si & Mn & C \\
\hline 42C & Bal. & 16 & 2 & & & & 1.0 & 1.0 & 0.2 \\
41C & Bal. & 17 & 12 & 2.5 & - & - & 2.3 & - & 0.03 \\
3533 & Bal. & 28 & 16 & 4.6 & - & - & 1.4 & 0.8 & 1.9 \\
MM23 & Bal. & 4.2 & - & 5 & 6.4 & 3.1 & - & - & 1.3 \\
\hline
\end{tabular}

\section{Results}

Figure 1 shows the microstructure of three coatings deposited at various speeds, namely 41C, 3533 and MM23 steel. Microstructure observations on 42C coatings did not result in such a clear picture as shown in Figure 1, but an estimate of the average size of the structural units was possible [13]. In Figure 1 one may see that for all these alloys, refinement of the microstructure increases with increasing cladding speed. In addition, the Backscatter Electron (BSE) images of Figure 1(d) to 1(i) suggest that in the case of 3533 and MM23 coating the constitution of the interdendritic phases has also changed, as confirmed later by the EDS/EBSD phase identification.

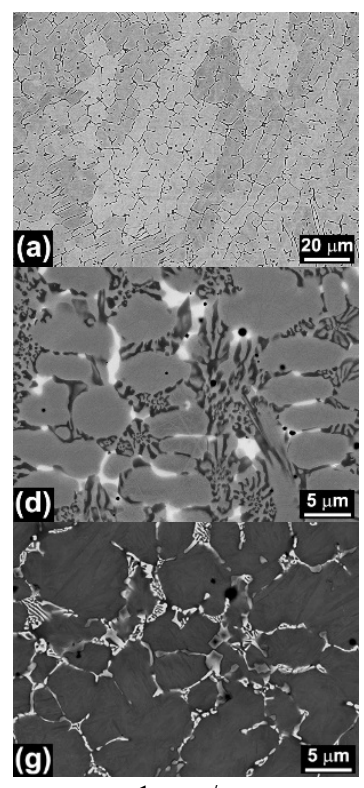

$1 \mathrm{~mm} / \mathrm{s}$

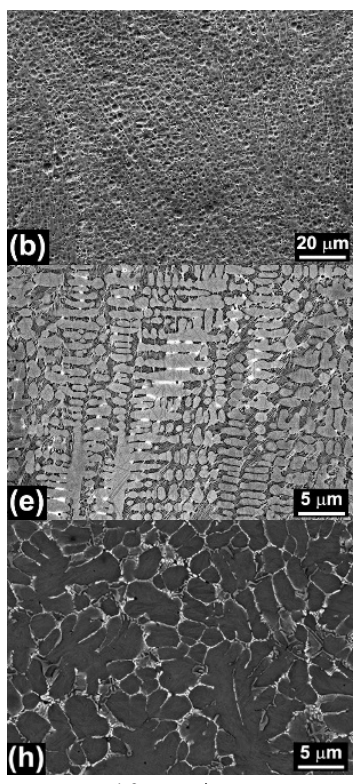

$10 \mathrm{~mm} / \mathrm{s}$

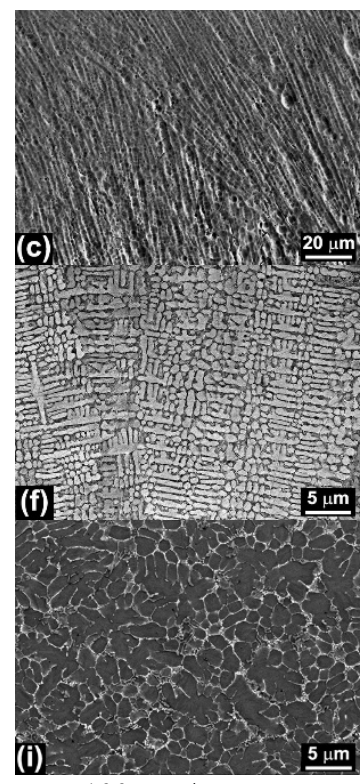

$100 \mathrm{~mm} / \mathrm{s}$

Figure 1: $\quad$ SEM-BSE images showing the microstructure of 41C (a)-(c), 3553 (d)-(f) and MM23 (g)-(i) coatings at three different cladding speeds. 
In this work, Dendritic Arm Spacing (DAS) and cell size are referred to as "characteristic size" of the microstructure, because they characterize the scale. In this context, the characteristic size is different from the grain size because grains usually contain many dendritic or cellular arms. Figure 2 shows the EBSD grain map for one of the 3533 coatings. The difference between the grain size and characteristic size is clearly visible. Estimation of cooling rates has been done for each coating material and processing speed separately using a numerical approach [11]. Similar cooling rates were achieved for different steels at a given processing speed. Namely, $1 \times 10^{3}, 20 \times 10^{3}$ and $350 \times 10^{3} \mathrm{~K} / \mathrm{s}$, for processing speeds 1,10 and $100 \mathrm{~mm} / \mathrm{s}$, respectively. It is concluded that upon increasing the cladding speed from $1 \mathrm{~mm} / \mathrm{s}$ to $100 \mathrm{~mm} / \mathrm{s}$ the cooling rate increased roughly two orders of magnitude and the characteristic size decreased substantially as shown in Figure 2(b).

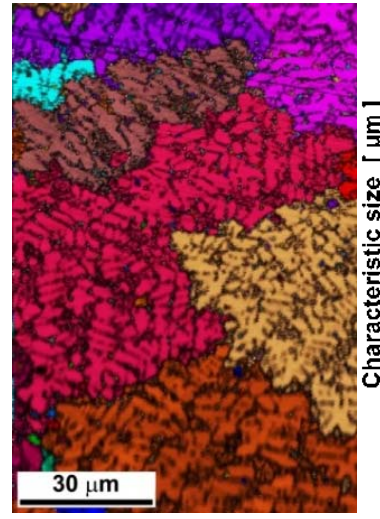

(a)

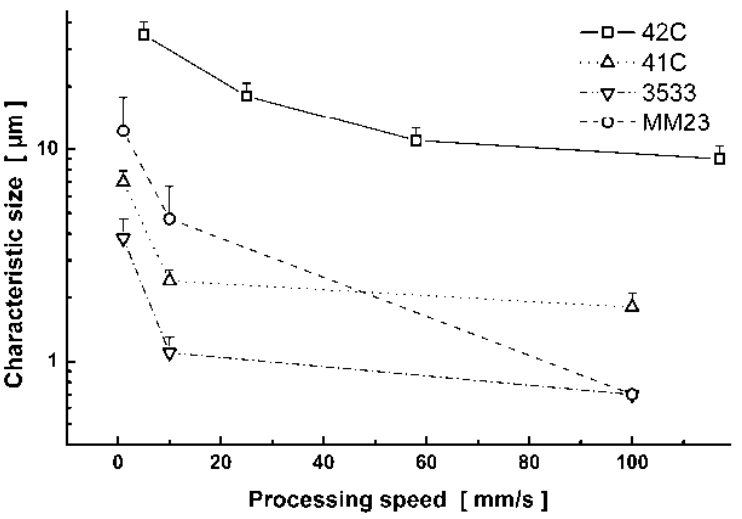

(b)

Figure 2: EBSD grain map (combined with image quality map) showing the grain and sub-grain structure of a 3533 coating (a). Variation of characteristic size of microstructure as a function of cladding speed for all four steels (b).

Despite the significant microstructural refinement in all cases, the hardness of the coatings shows a different behavior. It remains unaffected (MM23), either increased (41C and 3533) or decreased (41C) by a small amount as shown in Figure 3. Hardness of $41 \mathrm{C}$ and 3533 increased around 10 and 20 percent, respectively. Hardness of martensitic $42 \mathrm{C}$ is decreasing with increasing cooling rate. To explain better the observed microstructure-hardness relationship, the effect of cooling rate on phase constitution of the coatings should also be assessed. EBSD scans across entire sections of 41C coatings showed that at higher cladding speeds, smaller and more elongated grains are formed as shown in Figure 4. In addition, the amount of ferrite decreased from $4.8 \%$ to $1.8 \%$ as the cladding speed increased from $1 \mathrm{~mm} / \mathrm{s}$ to $100 \mathrm{~mm} / \mathrm{s}$. Retained austenite was measured in $42 \mathrm{C}$ coatings deposited at two extreme cladding speeds, namely 5 and $117 \mathrm{~mm} / \mathrm{s}$ as 2.5 and $12.5 \mathrm{vol} \%$, respectively. 


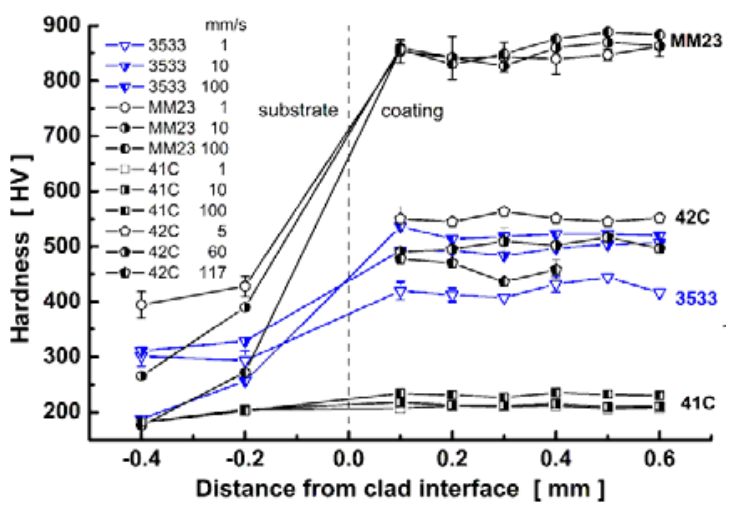

Figure 3: Variation of hardness as a function of cladding speed.
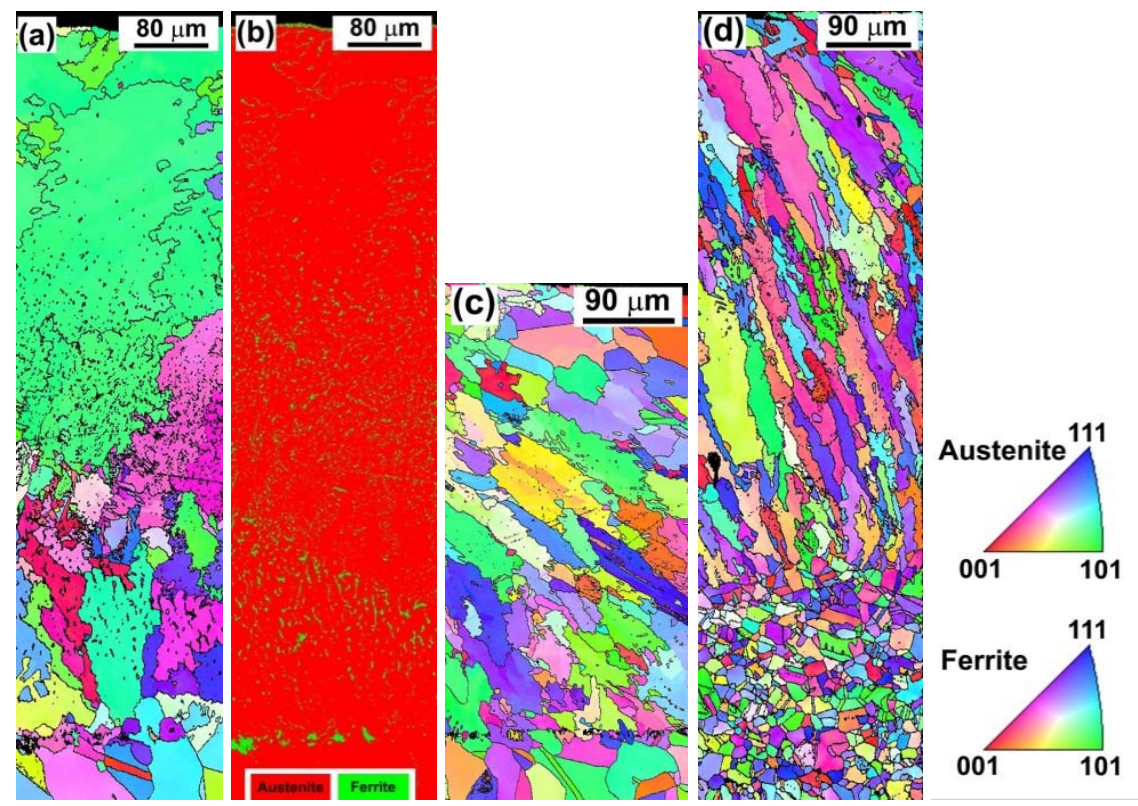

Figure 4: OIM inverse pole figure maps showing the grain structure of 41C coatings deposited at (a) $1 \mathrm{~mm} / \mathrm{s}$, (c) $10 \mathrm{~mm} / \mathrm{s}$ and (d) $100 \mathrm{~mm} / \mathrm{s}$. (b) shows the EBSD phase map for the coating in (a) with $4.8 \%$ ferrite and the balance austenite.

Figure 5 shows the distribution of Mo and $\mathrm{Cr}$ in the microstructure of 3533 coatings. Carbon existed in both $\mathrm{Cr}$ - and Mo-rich phases. Hence, the brighter and darker areas are Mo and $\mathrm{Cr}$ carbides, respectively. EBSD patterns from these carbides could be indexed as $\mathrm{Mo}_{2} \mathrm{C}$ and $\mathrm{Cr}_{7} \mathrm{C}_{3}$. The rest of the microstructure consists of austenite. The phase fractions for 3533 coatings deposited at $1 \mathrm{~mm} / \mathrm{s}$ 
and $100 \mathrm{~mm} / \mathrm{s}$ were measured as shown in Figure 5(d) and presented Table 2. It is seen that while the percentage of austenite remained roughly unchanged, more $\mathrm{Mo}_{2} \mathrm{C}$ existed in the coating deposited at $100 \mathrm{~mm} / \mathrm{s}$.
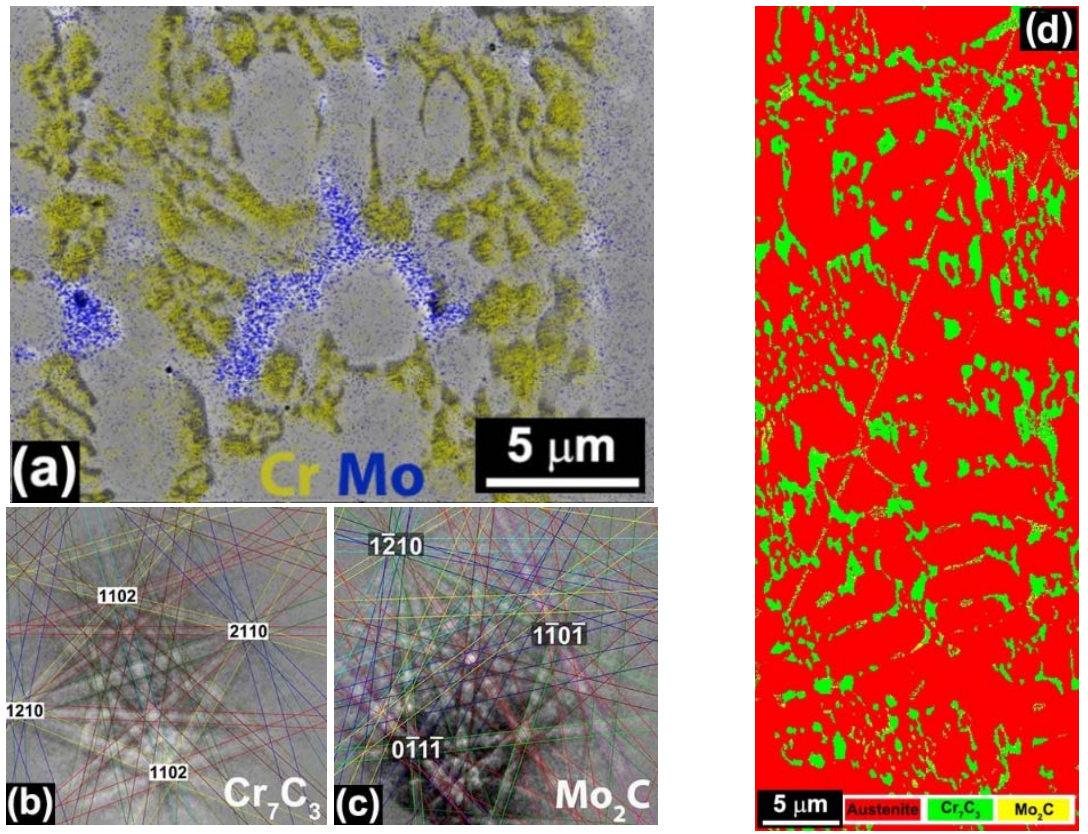

Figure 5: (a) EDS map shows the distribution of $\mathrm{Cr}$ and $\mathrm{Mo}$ in the microstructure of 3533 coatings; (b) and (c) indexed EBSD patterns from Cr- and Mo-rich areas; (d) EBSD phase map from a 3533 coating.

Table 2: $\quad$ Effect of processing speed on phase constitution of 3533 coatings.

\begin{tabular}{cccc}
\hline $\begin{array}{c}\text { Cladding speed } \\
(\mathrm{mm} / \mathrm{s})\end{array}$ & $\begin{array}{c}\mathrm{Cr}_{7} \mathrm{C}_{3} \\
(\%)\end{array}$ & $\begin{array}{c}\mathrm{Mo}_{2} \mathrm{C} \\
(\%)\end{array}$ & $\begin{array}{c}\text { Austenite } \\
(\%)\end{array}$ \\
\hline 1 & 14.5 & 1.4 & 84.1 \\
100 & 10 & 6.3 & 83.7 \\
\hline
\end{tabular}

A similar procedure, i.e. assessing the elemental distributions by EDS and measuring phase fractions using EBSD was done for MM23 coatings deposited at $1 \mathrm{~mm} / \mathrm{s}$ and $100 \mathrm{~mm} / \mathrm{s}$. Figure 6(a) shows that the interdendritic network of MM23 coatings consists of $\mathrm{Mo}_{2} \mathrm{C}$ (layered) and $\mathrm{VC}$ (blocky) carbides. The rest of the microstructure is indexed as either martensite or austenite. Figure 6(d) shows the phase map for MM23 coating deposited at $1 \mathrm{~mm} / \mathrm{s}$ and Table 3 represents the effect of cladding speed on phase fractions of MM23 coatings. 
Because of the crystallographic similarity of VC and austenite (both FCC crystals, lattice parameters of $0.416 \mathrm{~nm}$ for $\mathrm{VC}$ and $0.365 \mathrm{~nm}$ for austenite), these two phases could be indexed as one another.
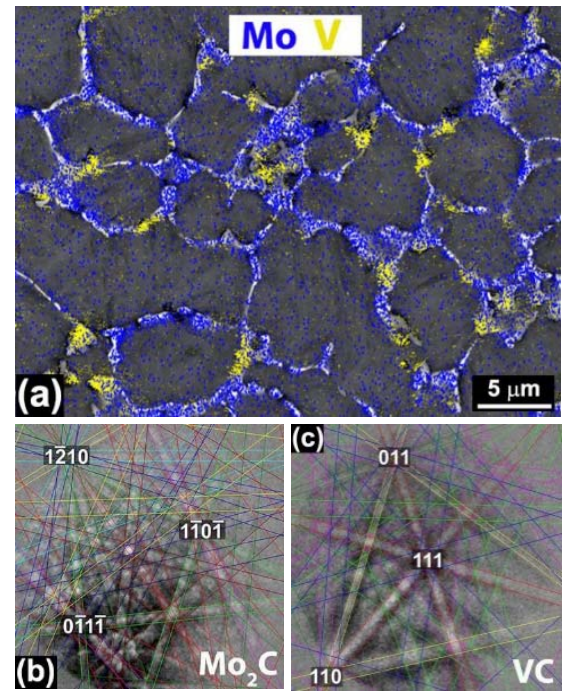

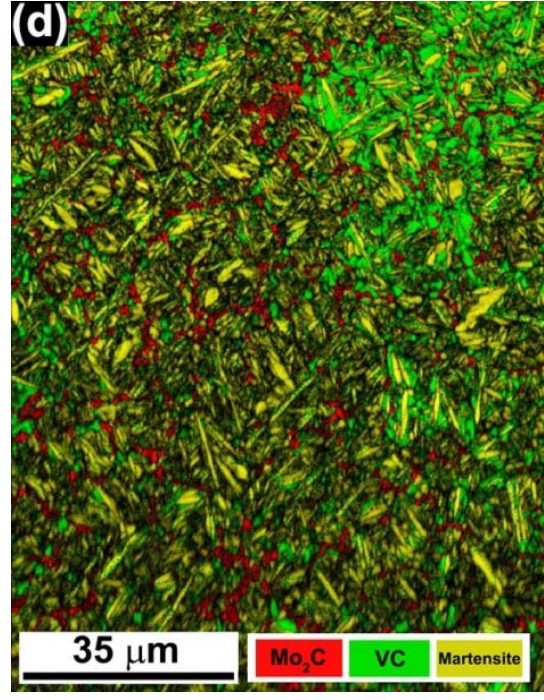

Figure 6: (a) EDS map showing the distribution of $\mathrm{Mo}$ and $\mathrm{V}$ in the microstructure of MM23 coatings, (b) and (c) EBSD pattern from Mo- and V-rich areas after indexing, (d) EBSD phase map from a MM23 coating.

Table 3: Effect of cladding speed on phase constitution of MM23 coatings.

\begin{tabular}{cccc}
\hline $\begin{array}{c}\text { Cladding speed } \\
(\mathrm{mm} / \mathrm{s})\end{array}$ & $\begin{array}{c}\text { Martensite } \\
(\%)\end{array}$ & $\begin{array}{c}\mathrm{Mo}_{2} \mathrm{C} \\
(\%)\end{array}$ & $\begin{array}{c}\mathrm{VC}+\text { Austenite } \\
(\%)\end{array}$ \\
\hline 1 & 51.2 & 21.6 & 27.2 \\
100 & 46.6 & 13.3 & 40.1 \\
\hline
\end{tabular}

Hence, Table 3 gives their combined percentages. Nevertheless, it is possible to say that more austenite is retained in the coating deposited at $100 \mathrm{~mm} / \mathrm{s}$ based on the lower content of martensite. Table 3 also shows that increasing the cladding speed (i.e. cooling rate) significantly influenced the amount of carbide phases. At higher speeds, more $\mathrm{VC}$ formed at the expense of $\mathrm{Mo}_{2} \mathrm{C}$.

\section{Discussion}

It is shown that while faster laser cladding and the subsequent increase in the cooling rate refines the microstructure of the coatings, it does not always improve their hardness. Contrary to the case of multi-layer deposits of AISI 431 
coatings [13], a decrease in hardness of martensitic 42C deposits with increasing cooling rate was observed. By increasing the cladding speed two general trends in the properties of the $42 \mathrm{C}$ coatings were observed: refinement of the solidification structure (smaller cell spacing) and stabilization of retained austenite. This implies that there is a correlation between cell spacing and austenite stabilization which appears below some threshold. It is known that during cooling of austenite, the transformation to martensite does not start until reaching the martensite start temperature $\left(M_{s}\right)$, and the extent of transformation at a certain temperature below $M_{s}$ depends on the difference between $M_{s}$ and that particular temperature [14]. In other words, if there is any parameter that can affect the extent of martensitic transformation at room temperature, it should affect the $M_{s}$ temperature.

Higher amounts of retained austenite, as observed in 42C and MM23 coatings with a very fine dendritic structure, show that the smaller cell spacing values obtained by faster solidification at higher cladding speeds stabilizes the austenite and delays the transformation to martensite by lowering the $M_{s}$ temperature. Microstructural investigation of the studied $42 \mathrm{C}$ coatings by SEM and OIM showed that martensite laths are stopped by the dendrite boundaries in various locations. Figure 7 shows examples of this observation for one of deposits. It can be seen that martensite lath is stopped at dendrite boundaries which means that dendrite boundaries act as effective obstacles against the growth of martensite laths.
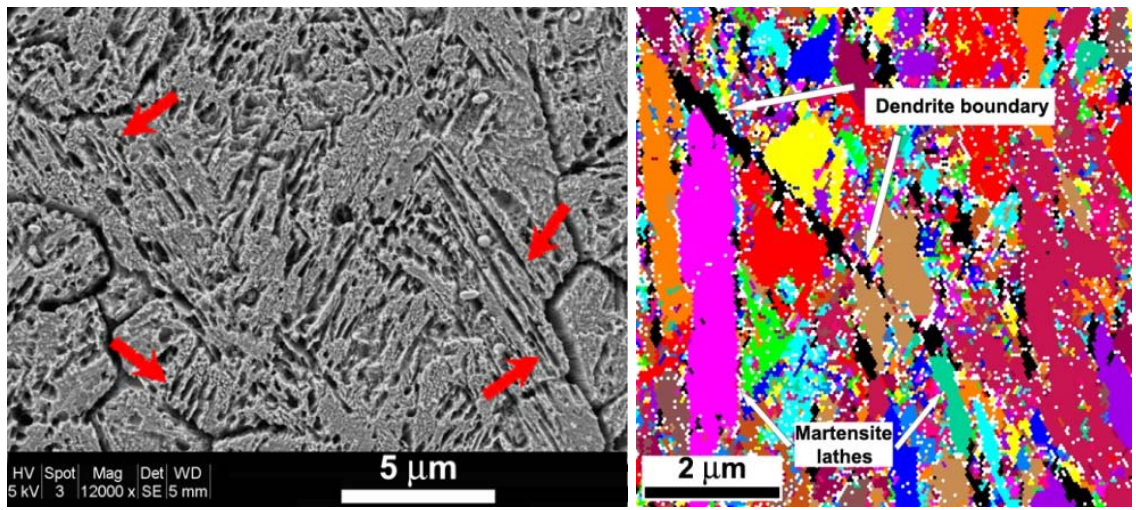

Figure 7: (a) SEM micrographs and (b) OIM grain map showing how martensite laths are halted at dendrite boundaries. Arrows show martensite laths in (a) and dendrite boundaries in (b).

On other three coatings the hardness improvements were either non-existing or marginal. In the case of $41 \mathrm{C}$ coatings, the Hall-Petch relationship could be used to correlate the hardness of the deposits to their characteristic size using the following equation:

$$
H=H_{0}+k / \sqrt{d}
$$


where $H$ is Hardness related to the yield stress, $d$ characteristic length scale involved and $H_{0}$ and $k$ are material constants. The value of $k$ reflects the obstacle strength of the boundary. This means that the hardness increase in $41 \mathrm{C}$ materials is fully due to microstructural refinement. For 3533 coatings, microstructural refinement was accompanied by a change in quantity of the carbides. In other words, higher cooling rates encouraged $\mathrm{Mo}_{2} \mathrm{C}$ at the expense of $\mathrm{Cr}_{7} \mathrm{C}_{3}$.

The hardness of various phases encountered in this study is presented in Table 4. It is seen that hardness of $\mathrm{Mo}_{2} \mathrm{C}$ is higher than that of $\mathrm{Cr}_{7} \mathrm{C}_{3}$. As a result, increasing the cooling rate caused slightly more improvement in the hardness of 3533 coatings than that of $41 \mathrm{C}$ coatings because for 3533 , not only reduction in characteristic size, but also replacement of some $\mathrm{Cr}_{7} \mathrm{C}_{3}$ with harder carbides contributed to the increase of hardness.

Table 4: Hardness of the phases on the laser clad coatings of this study [15].

\begin{tabular}{cccccc}
\hline Phase & Martensite & Austenite & $\mathbf{C r}_{7} \mathbf{C}_{3}$ & $\mathbf{M o}_{2} \mathbf{C}$ & $\mathbf{V C}$ \\
\hline Hardness (HV) & $500-1010$ & $250-350$ & 1200 & 1500 & 2800 \\
\hline
\end{tabular}

The synergistic effect of two strengthening mechanisms is also observed in the case of MM23 coatings. Here the amount of martensite and the quantity of carbides are affected because of variations in the cooling rate. Substantial refinement of austenite dendrites during solidification will increase the energy barrier to martensitic transformation. As a result, the martensite start $\left(\mathrm{M}_{\mathrm{s}}\right)$ temperature will decrease which will lower the amount of martensite at room temperature [13]. While such a reduction in the amount of martensite was observed for MM23 coatings, substitution of $\mathrm{Mo}_{2} \mathrm{C}$ by the much harder $\mathrm{VC}$ compensated for any loss of hardness. In the coatings investigated, more stable carbides have prevailed at higher cooling rates, i.e. $\mathrm{Mo}_{2} \mathrm{C}$ vs. $\mathrm{Cr}_{7} \mathrm{C}_{3}$ and $\mathrm{VC}$ vs. $\mathrm{Mo}_{2} \mathrm{C}$. Substitution of one carbide phase by another is an example of phase selection phenomena at higher cooling rates. In such conditions, the phase which could nucleate and or grow more easily forms at the expense of the other phase(s) [16].

\section{Conclusions}

The cooling rate plays an important role in the strengthening mechanism in laserclad steel coatings. In martensitic steel coatings the significant refinement of dendritic structure stabilizes the parent austenite phase which reduces the hardness of single layer coatings deposited at higher cladding speeds. If multiple strengthening mechanisms are operational, the hardness of their laser-clad coatings is determined by the synergistic effect of the all mechanisms. On one hand, microstructural refinement of austenite and selective precipitation of harder carbides increases the hardness. On the other hand, refinement of primary 
austenite could result in a decrease in hardness in the case of martensitic strengthening. Such an interplay between various mechanisms were observed for 3533 and MM23 coatings. In general, cladding at higher speeds does not substantially improve the hardness of laser-clad steel coatings.

\section{References}

[1] A. Frenk, \& W. Kurz, High speed laser cladding: solidification conditions and microstructure of a cobalt-based alloy, Mater. Sci. Eng. A. 173 (1993) 339-342.

[2] Y.P. Kathuria, Some aspects of laser surface cladding in the turbine industry, Surf. Coat. Technol. 132 (2000) 262-269. doi:10.1016/S02578972(00)00735-0.

[3] J. Singh, \& J. Mazumder, Microstructure and wear properties, Metall. Trans. A. 18 (1987) 313-322. doi:10.1007/BF02646165.

[4] W. Kurz, \& R. Trivedi, Rapid solidification processing and microstructure formation, Mater. Sci. Eng. A. 179-180 (1994) 46-51. doi:10.1016/09215093(94)90162-7.

[5] K. Partes, Analytical model of the catchment efficiency in high speed laser cladding, Surf. Coat. Technol. 204 (2009) 366-371. doi:10.1016/ j.surfcoat.2009.07.041.

[6] K. Partes, \& G. Sepold, Modulation of power density distribution in time and space for high speed laser cladding, J. Mater. Process. Technol. 195 (2008) 27-33. doi:10.1016/j.jmatprotec.2007.05.052.

[7] I. Hemmati, Laser-deposited metallic coatings, Zernike Institute, Applied Physics Department, University of Groningen, 2013. http://irs.ub.rug.nl/ppn/369175824.

[8] S. Nowotny, F. Brueckner, S. Thieme, C. Leyens, \& E. Beyer, Highperformance laser cladding with combined energy sources, J. Laser Appl. 27 (2015). doi:10.2351/1.4817455.

[9] E. Toyserkani, A. Khajepour, S. Corbin, Laser Cladding, CRC Press, Boca Raton, 2005.

[10] I. Hemmati, J.C. Rao, V. Ocelík, \& J.T.M. De Hosson, Electron Microscopy Characterization of Ni-Cr-B-Si-C Laser Deposited Coatings, Microsc. Microanal. 19 (2013) 120-131. doi:10.1017/ S1431927612013839.

[11] N.A. Berjeza, S.P. Velikevitch, V.I. Mazhukin, I. Smurov, \& G. Flamant, Influence of temperature gradient to solidification velocity ratio on the structure transformation in pulsed- and CW-laser surface treatment, Appl. Surf. Sci. 86 (1995) 303-309.

[12] ASM handbook, 10th ed, ASM International, Materials Park, OH, 1990.

[13] I. Hemmati, V. Ocelík, \& J.T.M. De Hosson, The effect of cladding speed on phase constitution and properties of AISI 431 stainless steel laser deposited coatings, Surf. Coat. Technol. 205 (2011) 5235-5239. 
[14] D. Koistinen, \& R. Marburger, A General Equation Prescribing the Extent of the Austenite-Martensite Transformation in Pure Iron-Carbon Alloys and Plain Carbon Steels, Acta Metall. 7 (1959) 59-60.

[15] J.R. Davis ed., Cast irons, ASM International, Materials Park, OH, 1996.

[16] M. Li, S. Ozawa, \& K. Kuribayashi, On determining the phase-selection principle in solidification from undercooled melts - Competitive nucleation or competitive growth?, Philos. Mag. Lett. 84 (2004) 483-493. 